\title{
Reativação e distribuição do DNA latente do herpesvírus bovino tipo 5 no encéfalo de ovinos infectados experimentalmente ${ }^{1}$
}

\author{
Gustavo Cauduro Cadore², Deniz Anziliero², Rudi Weiblen ${ }^{3}$ e Eduardo F. Flores ${ }^{3 *}$
}

\begin{abstract}
Cadore G.C., Anziliero D., Weiblen R. \& Flores E.F. 2011. [Reactivation and distribution of bovine herpesvirus 5 DNA in the brain of latently infected sheep.] Reativação e distribuição do DNA latente do herpesvírus bovino tipo 5 no encéfalo de ovinos infectados experimentalmente. Pesquisa Veterinária Brasileira 31(12):1090-1096. Departamento de Medicina Veterinária Preventiva, Universidade Federal de Santa Maria, Camobi, Santa Maria, RS 97105-900, Brazil. E-mail: eduardofurtadoflores@gmail.com

The biology of latent infection by bovine herpesvirus type 5 (BoHV-5) has been studied in cattle and rabbits, yet many aspects remain poorly understood. We herein investigated the suitability of lambs to investigate aspects of BoHV-5 latency. Thirteen six-month-old lambs inoculated intranasally (IN) with BoHV-5 strain SV-507/99 (titer of $10^{6.8}$ TCID $_{50}$ / $\mathrm{mL}$ ) shed the virus in nasal secretions in titers up $10^{5.5} \mathrm{TCID}_{50} / \mathrm{mL}$, during up to 11 days, developing virus neutralizing (VN) titers of 16 to 128 at day 30 post-inoculation (pi). The inoculated animals developed only a mild serous nasal secretion and transient hyperthermia. Examination of brain sections of five lambs euthanized at day 30 pi by PCR revealed the presence of latent DNA in the trigeminal ganglia (TG, 5 out of five), olfactory bulbs (OB, $5 / 5)$, pons $(2 / 5)$, cerebellum $(2 / 5)$ and cerebral cortex $(1 / 5)$. Administration of dexamethasone $(D x, n=4)$ or flumethasone (FluM, $n=4)$ to eight latently infected lambs at day 65 pi resulted in virus reactivation and shedding by 3 out of 4 individuals in each group. Virus shedding in nasal secretions started at day 3 post-treatment and lasted up to five days (1-5) in Dx treated lambs (titers up to $10^{2.8} \mathrm{TCID}_{50} / \mathrm{mL}$ ), was delayed and lasted up to three days (1-3) in FluM-treated lambs (titers up to $10^{2.1} \mathrm{TCID}_{50} / \mathrm{mL}$ ). PCR examination of the brains of animals submitted to reactivation, at day 30 post-treatment, showed a pattern of distribution of latent viral DNA fairly similar to that found in those not submitted to reactivation. In summary, the ability of BoHV-5 to establish latent infection, the consistent colonization of TGs and OBs by latent viral DNA and virus reactivation induced by corticosteroid treatment are promising findings towards the use of lambs to study selected aspects of BoHV-5 latency.
\end{abstract}

INDEX TERMS: BoHV-5, latency, lambs, animal model, corticoids.

RESUMO.- A biologia da infecção latente pelo herpesvírus bovino tipo 5 (BoHV-5) tem sido estudada em bovinos e coelhos, mas vários aspectos permanecem desconhecidos. Este artigo relata uma avaliação de ovinos jovens como modelo para o estudo da infecção latente pelo BoHV-5. Treze

\footnotetext{
${ }^{1}$ Recebido em 12 de julho de 2011.

Aceito para publicação em 14 de setembro de 2011.

${ }^{2}$ Programa de Pós-Graduação em Medicina Veterinária (PPGMV), Universidade Federal de Santa Maria (UFSM), Avenida Roraima 1000, Camobi, Santa Maria, RS 97105-900.

${ }^{3}$ Setor de Virologia, Departamento de Medicina Veterinária Preventiva (DMVP), Centro de Ciências Rurais (CCR), Universidade Federal de Santa Maria (UFSM), Camobi, Santa Maria, RS 97105-900, Brasil. *Autor para correspondência: eduardofurtadoflores@gmail.com
}

cordeiros com idade entre seis e sete meses, inoculados pela via intranasal (IN) com a cepa SV-507/99 do BoHV5 (título de $10^{6,8} \mathrm{DICC}_{50} / \mathrm{mL}$ ) excretaram o vírus em secreções nasais em títulos de até $10^{5,5} \mathrm{DICC}_{50} / \mathrm{mL}$, com duração de até 11 dias, desenvolvendo anticorpos neutralizantes em títulos de 16 a 128 no dia 30 pós-inoculação (pi). Os ovinos inoculados apresentaram apenas secreção nasal serosa leve e hipertermia transitória. 0 PCR de secções do encéfalo de cinco animais inoculados no dia 30 pi revelou a presença de DNA viral latente nos gânglios trigêmeos (TG, 5 de 5 animais), bulbo olfatório (BO, $5 / 5)$, ponte $(2 / 5)$, cerebelo $(2 / 5)$, córtex cerebral $(1 / 5)$. Administração de dexametasona ( $D x, n=4$ ) ou flumetasona (FluM, $n=4$ ) a oito ovinos no dia 65 pi resultou em reativação e excreção viral por 3 de 4 
animais de cada grupo. A excreção viral nas secreções nasais iniciou no dia 3 pós-tratamento e durou entre 1 e 5 dias nos ovinos tratados com Dx (títulos até $10^{2,8} \mathrm{TCID}_{50} / \mathrm{mL}$ ) e foi mais tardia, durando entre 1 e 3 dias nos animais tratados com FluM (títulos de $10^{2,1} \mathrm{TCID}_{50} / \mathrm{mL}$ ). Uma análise por PCR do encéfalo dos animais submetidos à reativação, no dia 65 pós-infecção, revelou uma distribuição do DNA latente semelhante àquela observada nos animais não submetidos à reativação. Em resumo, a capacidade do BoHV-5 estabelecer infecção latente, a colonização dos TGs a BOs com DNA viral latente e a reativação induzida por corticoides são achados promissores para o uso de cordeiros como modelo para a infecção latente pelo BoHV-5.

TERMOS DE INDEXAÇÃO.- BoHV-5, latência, cordeiros, modelo animal, corticoides.

\section{INTRODUÇÃO}

O herpesvírus bovino tipo 5 (BoHV-5) é um alfaherpesvírus neurovirulento, frequentemente associado com doença neurológica em bovinos jovens (Studdert 1990, Rissi et al. 2007). Casos esporádicos ou pequenos surtos da infecção pelo BoHV5 já foram relatados em vários países, mas a doença é particularmente frequente na Argentina e no Brasil, onde vários surtos tem sido relatados a cada ano (Carrillo et al. 1983, Riet-Correa et al. 1989, Weiblen et al. 1989, Salvador et al. 1998, Rissi et al. 2007). Nestes países, a doença neurológica pelo BoHV-5 possui grande repercussão sanitária e econômica, muitas vezes confundindo-se com a raiva, a causa mais comum de encefalite em bovinos nas Américas (Barros et al. 2006). 0 BoHV-5 é genética e antigenicamente relacionado ao herpesvírus bovino tipo 1 (BoHV-1), agente da rinotraqueíte infecciosa (IBR), balanopostite e vulvovaginite pustular bovina (IPB/IPV) (Kahrs 2001). Assim como outros alfaherpesvírus, o BoHV-5 é capaz de estabelecer e reativar infecção latente em seus hospedeiros (Vogel et al. 2003).

Após replicação na mucosa nasal, o BoHV-5 invade as terminações nervosas locais e é transportado por fibras nervosas até o sistema nervoso central (SNC), onde replica ativamente e dissemina-se produzindo meningo-encefalite aguda de curso geralmente fatal (Bagust \& Clark 1972, Belknap et al. 1994). Em alguns animais, a invasão do encéfalo é restrita e o vírus estabelece infecção latente nos gânglios trigêmeos (TG) e em outros sítios do SNC (Perez et al. 2002, Vogel et al. 2003). A infecção latente pode ser reativada naturalmente ou pode ser induzida pela administração de corticoides (Perez et al. 2002, Vogel et al. 2003). A patogenia da infecção neurológica pelo BoHV-5 tem sido estudada nos hospedeiros naturais (Belknap et al. 1994, Meyer et al. 2001, Perez et al. 2002, Vogel et al. 2003) e em modelos animais. Em particular, coelhos tem sido muito utilizados para estudar vários aspectos da neuropatogenia do BoHV-5, pois desenvolvem a infecção e doença neurológica similar àquela de bovinos (Meyer et al. 1996, Chowdhury et al. 1997, Silva et al. 1999a, Caron et al. 2002). Infecções experimentais com o BoHV-5 também foram realizadas com sucesso em caprinos (Diel et al. 2007) e em ovinos (Belák et al. 1999, Silva et al. 1999b).

Ovinos inoculados pela via intranasal excretam o vírus em títulos variáveis e podem, eventualmente, desenvolver doença neurológica (Belák et al. 1999, Silva et al. 1999b). Após a infecção aguda, o vírus estabelece infecção latente, podendo ser reativado e transmitido a sentinelas após a administração de corticoides (Silva et al. 1999b). Essas inoculações experimentais foram motivadas por uma possível participação de ovinos na epidemiologia do BoHV-5, devido a relatos de sorologia positiva ao vírus em rebanhos ovinos (Lindner et al. 1993). Essa hipótese, no entanto, mostrou-se improvável e, por isso, tem sido pouco considerada ao longo dos anos (Ackermann \& Engels 2006). Não obstante a improvável importância epidemiológica, a susceptibilidade de ovinos ao BoHV-5 pode ser explorada para estudar aspectos pouco conhecidos da infecção, sobretudo da infecção latente. Assim, o presente trabalho teve como objetivo caracterizar a infecção latente pela cepa SV-507/99 do BoHV-5 em ovinos jovens, com vistas à utilização desses animais como modelo experimental.

\section{MATERIAL E MÉTODOS}

\section{Desenho experimental}

Treze cordeiros foram inoculados pela via intranasal (IN) com o BoHV-5 (cepa SV-507/99), e dois cordeiros foram inoculados com meio essencial mínimo (MEM). Os animais foram submetidos a monitoramento clínico, virológico e sorológico nos dias seguintes à inoculação. No dia 30 pós-inoculação (pi), cinco cordeiros inoculados e um controle foram eutanasiados para a coleta do encéfalo. Várias secções do encéfalo foram coletadas individualmente e submetidas à reação da polimerase em cadeia (PCR) para a pesquisa de DNA viral latente. Os cordeiros restantes foram submetidos a tratamento com corticoides no dia 65 pi, e monitorados nos dias seguintes ao tratamento. Trinta dias após, esses animais foram eutanasiados para a coleta do encéfalo para pesquisa de DNA viral por PCR.

\section{Células e vírus}

Para a multiplicação, quantificação, isolamento viral e testes de soro-neutralização (SN) foram utilizadas células de linhagem de rim bovino CRIB (Flores \& Donis 1995), cultivadas em meio essencial mínimo (MEM), contendo penicilina $(1,6 \mathrm{mg} / \mathrm{L})$, estreptomicina $(0,4 \mathrm{mg} / \mathrm{L})$, suplementado com $5 \%$ de soro fetal bovino (SFB - Cultilab, Campinas, Brasil). 0 vírus utilizado para a inoculação foi a cepa SV-507/99, isolada de um surto de meningoencefalite no sul do Brasil (Delhon et al. 2003). 0 inóculo consistiu de $2 \mathrm{~mL}$ de suspensão viral contendo $10^{6,8} \mathrm{DICC}_{50} / \mathrm{mL}$.

\section{Animais, inoculação de vírus e monitoramento}

Foram utilizados 15 cordeiros da raça Ideal, de ambos os sexos, com idade entre 6 e 7 meses. Treze animais foram inoculados com $2 \mathrm{~mL}$ da suspensão viral IN (1 mL em cada narina). Dois animais foram mantidos como controles e foram inoculados com MEM. Após inoculação, os animais foram avaliados clinicamente (coloração e secreção na mucosa nasal, sinais respiratórios e sistêmicos). Suabes nasais foram coletados diariamente durante 15 dias e amostras de sangue para sorologia foram coletadas nos dias zero (dia da inoculação), 15, 30, 65 (dia do início da administração de corticoides) e 80 dias pi. Também foram coletados suabes nasais a intervalos semanais até o dia da administração de corticoides.

Os suabes foram submetidos à pesquisa de vírus, em monocamadas de células CRIB, sendo submetidos a três passagens de cinco dias cada. As amostras que foram positivas para vírus foram 
posteriormente quantificadas pela técnica de diluição limitante, e os títulos foram calculados de acordo com Reed \& Muench (1938) e expressos como $\log _{10}$ doses infectantes para $50 \%$ dos cultivos celulares por $\mathrm{mL}$ (DICC $/ \mathrm{mL}$ ). As amostras de soro foram submetidas à técnica de soroneutralização (SN) em microplacas para a pesquisa de anticorpos neutralizantes contra o vírus homólogo, conforme descrito por Vogel et al. (2003).

Trinta dias após a inoculação (pi), cinco animais inoculados e um controle foram submetidos à eutanásia para a coleta do encéfalo para pesquisa de DNA latente. Foram coletadas individualmente as seguintes secções: gânglios trigêmeos (TG), bulbo olfatório (BO), tálamo (TA), ponte (PO), cerebelo (CB) e córtex cerebral (CC), este sendo um pool dos córtices anterior/parietal/ocipital.

\section{Reativação da infecção}

No dia 65 pi, os animais restantes $(n=8)$ foram alocados em dois grupos de quatro animais cada e submetidos a administração de corticoides, na tentativa de reativar a infecção latente. Ambos os grupos receberam cinco administrações, em dias consecutivos, do respectivo fármaco, pela via intramuscular. 0 grupo I (Cordeiros $1,6,8,12)$ recebeu acetato de dexametasona (Decadronal ${ }^{\circledR}$, Aché) na dose de $0,2 \mathrm{mg} / \mathrm{kg} /$ dia. 0 grupo II (Cordeiros 2, 4, 5 e 11) recebeu Flumetasona (Flucortan $\AA$, Fort Dodge) na dose de $0,15 \mathrm{mg} / \mathrm{kg} /$ dia. 0 animal controle recebeu o tratamento com Dx. Durante 15 dias consecutivos após o tratamento, suabes nasais foram coletados para a pesquisa de vírus. Sangue foi coletado para sorologia no dia 15 após a administração de corticóides.

Trinta dias após o início do tratamento com corticóides, cinco dos cordeiros inoculados que receberam o tratamento com corticoides foram submetidos à eutanásia para a coleta do encéfalo para pesquisa de DNA latente, como já descrito na infecção aguda. Três animais inoculados morreram de causas não relacionadas e não foram incluídos na fase final do experimento.

\section{Extração de DNA e nested PCR}

O DNA total dos tecidos foi extraído de aproximadamente $150 \mathrm{mg}$ de cada amostra tecidual. Os fragmentos de tecido foram submetidos à digestão com proteinase $\mathrm{K}(20 \mathrm{mg} / \mathrm{mL})$ e RNAse A $(10 \mathrm{mg} / \mathrm{mL})$ em tampão de digestão $(0,01 \mathrm{M}$ Tris; 0,001M EDTA; $0,1 \mathrm{M} \mathrm{NaCl} ; 1 \%$ SDS; pH 7,4) e submetidos a extração de DNA total com fenol-clorofórmio-álcool isoamílico (25:24:1) de acordo com Vogel et al. (2003). Após a extração, a concentração de DNA em cada amostra foi mensurada através de absorbância por luz ultravioleta a $260 \mathrm{~nm}$.
O DNA total extraído das amostras teciduais foi submetido a uma reação de nested PCR conforme Diel et al. (2007), utilizando-se iniciadores para a região codificante do gene da glicoproteína B: posições 57,338 e 57,782 (iniciadores externos 1 e 2) e 57,143 e 57,416 (iniciadores internos 3 e 4). As condições utilizadas para realização do PCR foram: denaturação inicial $\left(94^{\circ} \mathrm{C}\right.$ por $\left.10 \mathrm{~min}\right)$, seguidos por 35 ciclos de denaturação $\left(94^{\circ} \mathrm{C}\right.$ por 45 segundos), anelamento $\left(56^{\circ} \mathrm{C}\right.$ por 45 segundos) e extensão $\left(72^{\circ} \mathrm{C}\right.$ por 45 segundos); com uma extensão final $\left(72^{\circ} \mathrm{C}\right.$ por 10 minutos). Como controles positivos e negativos foram utilizadas secções do encéfalo de bezerros inoculados com o BoHV-5 e que foram positivas para vírus no isolamento em cultivo celular, e encéfalo de um animal não inoculado, respectivamente.

As secções do encéfalo que foram positivas para DNA viral por PCR foram posteriormente submetidas a tentativas de isolamento viral. Para isso, homogenados teciduais (10\% peso/volume) foram inoculados em células CRIB e submetidos a três passagens de 5 dias cada.

Os experimentos com animais foram aprovados pelo Comitê de Ética em Pesquisa da UFSM (Proc.\#23081-013798).

\section{RESULTADOS}

Durante a infecção aguda, todos os cordeiros inoculados com o BoHV-5 excretaram o vírus nas secreções nasais, com duração e títulos variáveis (Quadro 1). Em dois cordeiros, a excreção viral foi detectada até o dia 11 pi, porém a maioria cessou a excreção nos dias 6 e 7 pi. Em alguns animais a excreção foi detectada de forma intermitente. 0 pico de excreção viral ocorreu entre os dias 2 e 3 pi, com títulos médios de $10^{4,2} \mathrm{DICC}_{50} / \mathrm{mL}$ e $10^{3,2} \mathrm{DICC}_{50} / \mathrm{mL}$ respectivamente, e título máximo $10^{5,5} \mathrm{DICC}_{50} / \mathrm{mL}$ no dia 2 pi. Não foi detectada infectividade nas secreções nasais coletadas após o dia 12 pi, caracterizando o final da infecção aguda. Alguns animais inoculados apresentaram um discreto corrimento nasal seroso, leve hiperemia da mucosa nasal e hipertermia transitória, com duração de 1 a 4 dias, atingindo $42^{\circ} \mathrm{C}$. Todos os animais desenvolveram anticorpos contra ao BoHV-5 após a infecção aguda, apresentando títulos neutralizantes entre 16 a 128 no dia 30 pi (Quadro 1). Esses resultados demonstram que o BoHV-5 SV-507/99 replicou com eficiência na cavidade nasal dos ovinos, sendo excretado em títulos moderados por vários dias. Os títulos

Quadro 1. Excreção viral em secreções nasais durante infecção aguda em cordeiros inoculados com herpesvírus bovino tipo 5 (BoHV-5) e título de anticorpos (Ac) neutralizantes aos 30 dias pós-inoculação viral (dpi)

\begin{tabular}{|c|c|c|c|c|c|c|c|c|c|c|c|c|c|}
\hline \multirow[t]{2}{*}{ Animal } & \multicolumn{12}{|c|}{ Excreção viral dpi } & \multirow{2}{*}{$\begin{array}{c}\text { Título Ac } \\
\text { neutralizantes } \\
\text { (30dpi) }\end{array}$} \\
\hline & 1 & 2 & 3 & 4 & 5 & 6 & 7 & 8 & 9 & 10 & 11 & $12-15$ & \\
\hline 1 & $3,0^{\mathrm{a}}$ & 5,1 & 2,1 & 3,8 & 1,9 & 3,8 & -b & - & - & - & - & - & 64 \\
\hline 2 & 3,3 & 4,0 & 2,5 & 2,0 & $+^{c}$ & 2,7 & - & - & - & - & - & - & 64 \\
\hline 3 & 4,7 & 5,5 & 3,7 & 2,8 & 4,9 & 3,9 & - & - & - & - & + & - & 64 \\
\hline 4 & 2,3 & 5,1 & 2,5 & 2,1 & 3,1 & 1,9 & - & - & - & - & - & - & 128 \\
\hline 5 & 3,0 & 3,8 & 2,3 & 1,9 & 2,7 & 2,0 & 1,9 & - & - & - & - & - & 32 \\
\hline 6 & 4,0 & 4,0 & 3,3 & 2,7 & 4,7 & 3,7 & 1,9 & - & - & - & - & - & 32 \\
\hline 7 & 3,7 & 4,0 & 4,1 & 3,3 & 2,9 & 2,9 & 1,9 & + & + & - & - & - & 16 \\
\hline 8 & 3,3 & 3,7 & 4,0 & 2,1 & 2,8 & 2,9 & + & + & - & - & - & - & 64 \\
\hline 11 & 4,8 & 4,0 & + & + & 2,1 & 2,1 & + & 2,0 & + & - & + & - & 16 \\
\hline 12 & 2,5 & 4,3 & 4,9 & 3,3 & 3,9 & - & - & - & - & - & - & - & 32 \\
\hline 13 & 3,8 & 4,5 & 3,0 & 1,9 & 3,3 & 1,9 & - & - & - & - & - & - & 64 \\
\hline 14 & 2,1 & 2,7 & + & 2,1 & 3,1 & 1,9 & - & - & - & - & - & - & 32 \\
\hline 15 & 2,9 & 3,9 & 3,1 & 2,3 & 1,9 & - & - & - & - & - & - & - & 32 \\
\hline
\end{tabular}

$\overline{{ }^{a} \text { Título viral expresso } 10^{\times} \mathrm{DICC}_{50}} / \mathrm{mL}$; $^{\mathrm{b}}$ - Negativo para vírus; ${ }^{\mathrm{c}}+$ Positivo para vírus. 
de anticorpos neutralizantes desenvolvidos também demonstram a replicação viral eficiente. Os animais não desenvolveram sinais clínicos importantes, contrastando com a doença neurológica frequentemente desenvolvida por bezerros e coelhos inoculados com a cepa SV-507/99 (Vogel et al. 2003, Flores et al. 2009). Os dois cordeiros mantidos como controles permaneceram saudáveis durante o monitoramento, não excretaram vírus e permaneceram soronegativos. Os suabes nasais coletados a intervalos semanais até o dia da administração de corticoides foram negativos para vírus.

A distribuição do DNA latente do BoHV-5 no encéfalo dos cordeiros submetidos à eutanásia no dia 30 pi está apresentada no Quadro 2. O DNA viral foi detectado por PCR nos gânglio trigêmeos (5/5) e nos bulbos olfatórios $(5 / 5)$ de todos os animais avaliados. Também foi detectado, embora com menor frequência, na ponte $(2 / 5)$, cerebelo $(2 / 5)$ e córtex cerebral $(1 / 5)$. Todas as secções do encéfalo do animal controle foram negativas para DNA viral por PCR. Tentativas de isolamento de vírus das secções positivas no PCR foram negativas, indicando a presença de DNA sem replicação viral, o que caracteriza a infecção latente. Esses resultados demonstram que o BoHV-5 estabelece infecção latente no TG, BO e também em outros sítios do SNC de ovinos infectados experimentalmente.

A administração de corticoides (Dx ou FluM) a partir do dia 65 pi em oito animais inoculados com o BoHV-5 resultou na reativação viral em seis animais (75\%). Os dois fármacos resultaram em frequência igual de reativação ( 3 de 4 animais em cada grupo), porém os animais tratados com Dx apresentaram um período de excreção mais longo (Quadro 3). Em quatro animais, a excreção viral iniciou no dia 3 pós-tratamento (pt), com dois deles (grupo FluM) apresentando uma excreção mais tardia. Nos animais tratados com Dx, a média de excreção foi de 3,7 dias (1-5), e o título máximo foi de $10^{2,8}$ DICC $_{50} / \mathrm{mL}$. Nos animais tratados com FluM, a média de excreção foi de 2 dias, com título máximo de $10^{2,1}$ DICC $_{50} /$ mL. Além da excreção viral, dois animais do grupo Dx apresentaram um aumento (4x) no título de anticorpos neutralizantes. Os animais do grupo FluM, mesmo aqueles que excretaram o vírus, não apresentaram aumento igual ou maior que $4 x$ nos títulos. Não foram observadas alterações clínicas após a administração de corticoides. 0 animal controle não excretou vírus e permaneceu soronegativo após o tratamen-

Quadro 2. Detecção de DNA viral por PCR durante infecção latente (30 dias após a inoculação) em secções do encéfalo de ovinos infectados experimentalmente com o herpesvírus bovino tipo 5 (BoHV-5)

\begin{tabular}{ccccccc}
\hline Animal & \multicolumn{7}{c}{ Secção tecidual } \\
\cline { 2 - 7 } & BO & CC & TA & PO & CB & TG \\
\hline 3 & $+^{\mathrm{a}}$ & + & $-{ }^{\mathrm{b}}$ & - & + & + \\
7 & + & - & - & + & + & + \\
13 & + & - & - & - & - & + \\
14 & + & - & - & + & - & + \\
15 & + & - & - & - & - & +
\end{tabular}

$\overline{\mathrm{BO}}$ = bulbo olfatório; $\mathrm{CC}$ = córtex cerebral; $\mathrm{TA}$ = tálamo; $\mathrm{PO}=$ ponte; $\mathrm{CB}=$ cerebelo; TG = gânglio trigêmeo. ${ }^{\mathrm{a}}+$ Positivo para DNA viral; ${ }^{\mathrm{b}}-$ Negativo para DNA viral.
Quadro 3. Excreção viral em secreções nasais após administração de corticoides (dpt) e título de anticorpos (Ac) neutralizantes após tratamento com dexametasona (Dx) ou flumetasona (FluM) em ovinos inoculados com herpesvírus bovino tipo 5 (BoHV-5)

\begin{tabular}{|c|c|c|c|c|c|c|c|c|c|c|}
\hline \multirow{2}{*}{$\begin{array}{l}0 \\
0 \\
0 \\
0 \\
0 \\
0 \\
0\end{array}$} & \multirow[t]{2}{*}{ Animal } & \multicolumn{7}{|c|}{ Excreção viral dpt } & \multirow{2}{*}{$\begin{array}{c}\text { Título Ac } \\
\text { neutralizantes } \\
0 \mathrm{dpt}\end{array}$} & \multirow{2}{*}{$\begin{array}{c}\text { Título Ac } \\
\text { neutralizantes } \\
15 \mathrm{dpt}\end{array}$} \\
\hline & & $0-2$ & 3 & 4 & 5 & 6 & 7 & 8 & & \\
\hline \multirow{4}{*}{$\stackrel{x}{a}$} & 1 & $-{ }^{a}$ & $2,1^{b}$ & 2,7 & 2,8 & 1,9 & $+^{c}$ & - & 4 & 16 \\
\hline & 6 & - & 2,0 & 1,9 & 1,9 & - & + & - & 4 & 16 \\
\hline & 8 & - & - & - & - & - & - & - & 8 & 2 \\
\hline & 12 & - & 2,1 & - & - & - & - & - & 8 & 16 \\
\hline \multirow{4}{*}{$\sum_{\Xi}$} & 2 & - & - & - & - & - & 2,1 & + & 8 & 8 \\
\hline & 4 & - & - & - & - & + & 2,0 & + & 32 & 64 \\
\hline & 5 & - & 2,1 & - & - & - & - & - & 8 & 8 \\
\hline & 11 & - & - & - & - & - & - & - & 8 & 4 \\
\hline
\end{tabular}

a - Negativo para vírus; ${ }^{\mathrm{b}}$ Título viral expresso em $10^{\mathrm{x}} \mathrm{DICC}_{50} / \mathrm{mL}^{\mathrm{c}}{ }^{\mathrm{c}}+$ Positivo para vírus.

to com Dx. Esses resultados demonstram que o tratamento com corticoides foi capaz de reativar a infecção latente em $75 \%$ dos animais inoculados com o BoHV-5 SV-507/99. Embora o número pequeno de animais por grupo não permita grandes inferências, a Dx aparentemente foi mais efetiva em induzir reativação, resultando em excreção durante um período mais longo e em títulos maiores.

Cinco dos cordeiros que receberam tratamento para reativar a infecção foram posteriormente submetidos à eutanásia, no dia 30 pós-tratamento, para a pesquisa de DNA viral no encéfalo. A distribuição do DNA latente do BoHV-5 no encéfalo desses animais está apresentada no Quadro 4. O DNA viral foi detectado no bulbo olfatório e também no cerebelo em 4 de 5 cordeiros avaliados, no gânglio trigêmeo $(3 / 5)$ e na ponte $(2 / 5)$. No pool do córtex cerebral e no tálamo não foi detectado DNA viral em nenhum dos animais. Tentativas de isolamento viral das secções positivas no PCR resultaram negativas.

\section{DISCUSSÃO}

Dois estudos anteriores investigaram a susceptibilidade de ovinos à infecção pelo BoHV-5, com ênfase a uma possível participação dessa espécie na epidemiologia da infecção.

Quadro 4 . Detecção de DNA viral por PCR durante infecção latente (30 dias após a reativação) em diferentes secções do encéfalo de ovinos infectados experimentalmente com o herpesvírus bovino tipo 5 (BoHV-5)

\begin{tabular}{lcccccc}
\hline \multirow{2}{*}{ Animal } & \multicolumn{6}{c}{ Secção tecidual } \\
\cline { 2 - 7 } & BO & CC & TA & PO & CB & TG \\
\hline 1 & $+^{\mathrm{a}}$ & $-{ }^{\mathrm{b}}$ & - & - & + & - \\
2 & + & - & - & + & + & + \\
4 & + & - & - & - & + & + \\
5 & - & - & - & - & + & + \\
6 & + & - & - & + & - & - \\
BO = bulbo olfatório; CC = córtex cerebral; TA = tálamo; PO = ponte; CB = \\
cerebelo; TG = gânglio trigêmeo. ${ }^{\text {a }}+$ Positivo para DNA viral; ${ }^{\text {b }}$ - Negativo \\
para DNA viral.
\end{tabular}


Foi demonstrado que cordeiros são susceptíveis à infecção pela cepa de referência N569. Dois entre quatro cordeiros inoculados pela via nasal desenvolveram doença neurológica aguda, que foi descrita em seus aspectos clínicos e patológicos (Belák et al. 1999). Outro estudo envolveu a inoculação de dois isolados sul-americanos do BoHV-5 (EVI-88 e A663) em cordeiros, em que os animais inoculados excretaram o vírus por vários dias e um deles desenvolveu doença neurológica com características clínicas e patológicas semelhantes àquelas desenvolvidas por bovinos. Neste mesmo estudo foi possível demonstrar a reativação experimental da infecção e a transmissão do vírus a animais sentinela, reforçando a hipótese epidemiológica (Silva et al. 1999b). No entanto, a hipótese da participação de ovinos na transmissão do BoHV-5 na natureza não acumulou evidências e tem sido pouco considerada a partir de então. Da mesma forma, a susceptibilidade de ovinos ao BoHV-5 não foi posteriormente explorada. Assim, o presente trabalho foi realizado para estudar a susceptibilidade dessa espécie, avaliando sua adequação como modelo experimental para o BoHV-5, sobretudo para estudos da infecção latente.

Além dos ovinos possuírem algumas propriedades desejáveis em um modelo animal, a presente investigação justifica-se por vários aspectos; (i) a cepa SV-507/99 constitui-se na cepa mais estudada e melhor caracterizada de BoHV-5, tanto em nível molecular quanto biológico. Durante anos, esta cepa foi submetida a diversos estudos de patogenia em bovinos (Vogel et al. 2002, 2003), coelhos (Silva et al. 1999a, Beltrão et al. 2000, Caron et al. 2002, Mayer et al. 2006, Dezengrini et al. 2009) e caprinos (Diel et al. 2007). O SV-507/99 foi submetido ao sequenciamento completo do genoma, sendo a primeira cepa de herpesvírus bovino a ter a sua sequência genômica inteiramente determinada (Delhon et al. 2003). Apesar de sua extensiva caracterização, a cepa SV-507/99 ainda não havia sido inoculada em ovinos, desconhecendo-se a sua biologia e o seu potencial neurovirulento nessa espécie; (ii) a cepa SV-507/99 tem sido alvo de manipulação genética para a produção de mutantes defectivos em genes específicos, como a glicoproteína $\mathrm{E}$ ( $\mathrm{gE}$ ) e enzima timidina quinase (TK), e ambos gE/TK (Brum et al. 2010). 0 fenótipo desses recombinantes tem sido estudado em coelhos (Silva et al. 2010) e em bezerros (Santos et al. 2010). Os recombinantes defectivos na gE, TK e ambos gE/TK também tem sido avaliados como candidatos a cepas vacinais (Anziliero et al. 2011). Assim, um modelo animal teria uma grande utilidade para estudos de fenótipos de recombinantes do BoHV-5 defectivos em genes específicos; (iii) a maior proximidade filogenética entre ovinos e bovinos, hospedeiros naturais do BoHV-5. Essa proximidade certamente representa uma vantagem em relação aos coelhos - outra espécie utilizada como modelo para o BoHV-5, pois teoricamente produz achados mais similares e extrapoláveis aos observados em bovinos; (iv) a maior resistência dos ovinos à infecção neurológica aguda, o que resulta em taxas de sobrevivência compatíveis com estudos da infecção latente. Os coelhos são muito susceptíveis à infecção neurológica aguda pelo SV-507/99 e, mesmo quando inoculados com doses virais baixas, grande parcela dos animais sucumbe à infecção aguda (Mayer et al. 2006, Flores et al. 2009). Isso reduz muito o número de animais que sobrevivem para estudos da infecção latente. Assim, é necessário um número grande de animais e/ou doses de vírus progressivamente mais baixas, o que pode comprometer a qualidade dos achados. Mesmo os bovinos jovens são mais susceptíveis e sucumbem à infecção aguda com maior frequência do que os ovinos (Vogel et al. 2003). Dessa forma, ovinos jovens foram inoculados com a cepa SV-507/99 e monitorou-se a infecção aguda, a capacidade de reativação da infecção latente sob diferentes tratamentos e, finalmente, a distribuição do DNA viral latente no encéfalo pré e pós-reativação.

Durante a infecção aguda, a excreção viral nas secreções nasais estendeu-se até o dia 11 pi em dois animais, cessando entre os dias 6 e 7 pi na maioria deles. Os títulos de vírus nas secreções nasais atingiram $10^{5,5} \mathrm{TCID}_{50} / \mathrm{mL}$. No estudo de Belák et al. (1999), a excreção viral não foi quantificada, mas foi muito irregular e inconsistente entre os animais durando entre 3 e 10 dias. No experimento relatado por Silva et al. (1999b), os isolados sul-americanos do BoHV-5 foram excretados por até 15 dias, com títulos máximos de $10^{7,1}$ e $10^{5,9} \mathrm{TCID}_{50} / \mathrm{mL}$, para a cepa EVI-88 e A663 respectivamente. Nos experimentos realizados em bezerros (Beltrão 2000, Vogel et al. 2002, 2003), tanto os títulos virais excretados (até $10^{7,1} \mathrm{TCID}_{50} / \mathrm{mL}$ ) como a duração da excreção (até 18 dias em alguns animais) foram superiores ao observados no presente estudo. Essas diferenças não são surpreendentes e refletem a maior susceptibilidade de bovinos ao vírus. Não obstante, os níveis de replicação da cepa SV-507/99 durante a infecção aguda observada no presente estudo foram suficientes para o estabelecimento de latência nos animais inoculados. A soroconversão ao BoHV-5 observada em todos os animais inoculados, em títulos entre 16 e 128, também reflete a eficiência da replicação viral.

O estudo de Belák et al. (1999) concentrou-se na infecção aguda, não investigando a infecção latente. No estudo de Silva et al. (1999b), a frequência de reativação da infecção após administração de Dx em ovinos, foi de 2 entre 3 (isolado A663) e 8 de 10 (EVI-88), com duração média de excreção viral de 2,5 dias (A663) e 7,0 dias (EVI-88). No presente estudo, 3 de 4 ovinos de cada grupo (Dx e FluM) excretaram o vírus após o tratamento, e a duração média de excreção foi de 3,7 dias (Dx) e 2 dias (FluM). Em bovinos, a excreção do BoHV-5 após administração de Dx ocorre em títulos mais elevados (até $10^{7,1} \mathrm{TCID}_{50} / \mathrm{mL}$ ) e com maior duração (até 12 dias) (Vogel et al. 2002, 2003). No estudo de Silva et al. (1999b), independente das variações de frequência de reativação, duração e magnitude da excreção viral, os dois isolados foram reativados experimentalmente pela administração de Dx. A dose e o regime de administração de Dx utilizados naquele estudo foram os mesmos utilizados no presente experimento $(0,2 \mathrm{mg} / \mathrm{kg}$ durante cinco dias). Essa dose é aproximadamente duas vezes a dose utilizada na reativação do BoHV-1 e BoHV-5 em bezerros (Vogel et al. 2002, 2003). A FluM também demonstrou ser capaz de reativar a infecção latente pelo BoHV-5, embora resultando em excreção viral mais tardia e menos duradoura do que a induzida pela Dx (Quadro 3). Dessa forma, a Dx parece ser 
mais indicada para a reativação experimental da infecção latente pelo BoHV-5 em ovinos.

Além do TG - sítio mais consistente de latência dos alfaherpesvírus - o DNA latente do BoHV-5 SV-507/99 foi detectado consistentemente no BO e, também, com menor frequência, em outras áreas do encéfalo (Quadros 2 e 4). Essa distribuição apresenta um padrão um pouco mais restrito ao observado em bezerros (Vogel et al. 2003) e coelhos (Mayer et al. 2006). Nessas espécies, vários outros sítios de latência foram detectados no SNC, além do TG. A distribuição mais ampla do DNA latente do BoHV-5, em comparação com o BoHV-1, provavelmente deve-se a sua maior neuroinvasividade, que permite que o vírus atinja e estabeleça latência em regiões mais profundas do SNC (Vogel et al. 2003, Mayer et al. 2006). 0 significado desses sítios adicionais de latência pelo BoHV-5, no entanto, permanece desconhecido. É possível que possuam significado biológico, mas é também possível que sejam achados meramente circunstanciais (Vogel et al. 2003, Mayer et al. 2006).

A distribuição do DNA latente no encéfalo dos animais sacrificados 30 dias após a reativação não apresentou diferenças marcantes em relação aos examinados antes da reativação, com exceção de uma frequência maior no cerebelo (Quadros 2 e 4). Em bezerros e coelhos, a reativação da infecção é seguida de uma distribuição mais ampla do DNA latente, sugerindo que sítios adicionais são colonizados a partir de progênie viral produzida durante a reativação (Vogel et al. 2003, Mayer et al. 2006). 0 número pequeno de ovinos utilizados no presente estudo não permitiu que se investigasse esse aspecto com mais detalhes. A falha em detectar DNA latente em alguns TGs e OBs no dia 30 após administração de corticoides, possivelmente ocorreu devido a limitações de sensibilidade do PCR utilizado, visto que essas secções são geralmente positivas para DNA latente do BoHV-5 em bovinos (Vogel et al. 2003).

Em resumo, os resultados do presente estudo demonstram a susceptibilidade de ovinos ao BoHV-5, cepa SV507/99. Embora apresentem uma susceptibilidade aparentemente menor do que os bovinos - hospedeiros naturais do vírus - os ovinos suportam níveis moderados de replicação viral durante a infecção aguda. A replicação viral durante a infecção aguda foi suficiente para o estabelecimento da infecção latente em vários sítios do SNC, e o vírus foi reativado e excretado após a administração de corticoides. Assim, resguardadas as restrições inerentes ao uso de modelos animais, os ovinos parecem ser adequados para o estudo de aspectos da biologia da infecção latente pelo BoHV-5.

\section{REFERÊNCIAS}

Ackermann M. \& Engels M. 2006. Pro and contra IBR eradication. Vet. Microbiol. 113:293 302 .

Anziliero D., Santos C.M.B., Bauermann F.B., Cardozo L., Bernardes L.M., Brum M.C.S., Weiblen R. \& Flores E.F. 2011. A recombinant bovine herpesvirus 5 defective in thymidine kinase and glycoprotein $\mathrm{E}$ is atenuated and immunogenic for calves. Pesq. Vet. Bras. 31(1):23-30.

Bagust T.L. \& Clark L. 1972. Pathogenesis of meningo-encephalitis produced in calves by infectious bovine rhinotracheitis herpesvirus. J. Comp. Pathol. 82:375-383.

Barros C.S.L., Driemeier D., Dutra I.S. \& Lemos R.A.A. 2006. Doenças do Sistema Nervoso de Bovinos no Brasil. Vallée, Montes Claros, MG. 207p.
Belák L., Kucsera C., Ros G., Kulcsár L., Makranszki T.S. \& Belák S. 1999. Studies on the pathogenicity of bovine herpesvirus type 5 in sheep. Comp. Immunol. Microbiol. 22:207-220.

Beltrão N. 2000. Herpesvírus bovino tipo 5 (BoHV-5): infecção experimental de bovinos e utilização de coelhos como modelo. Dissertação de Mestrado, Universidade Federal de Santa Maria, Santa Maria, RS. 88p.

Beltrão N., Flores E.F., Weiblen R., Silva A.M., Roehe P.M. \& Irigoyen L.F. 2000. Infecção e enfermidade neurológica pelo herpesvírus bovino tipo 5 (BHV-5): coelhos como modelo experimental. Pesq. Vet. Bras. 20:144150.

Belknap E.B., Collins J.K., Ayers V.K. \& Schultheiss P.C. 1994. Experimental infection of neonatal calves with neurovirulent bovine herpesvirus type-5 (BHV-5). Vet. Pathol. 31:358-365.

Brum M.C., Weiblen R., Flores E.F. \& Chowdhury S.I. 2010. Construction and growth properties of bovine herpesvirus type 5 recombinants defective in the glycoprotein E or thymidine kinase gene or both. Braz. J. Med. Biol. Res. 43:217-224.

Caron L., Flores E.F., Weiblen R., Scherer C.F.C., Irigoyen L.F., Roehe P.M., Odeon A. \& Sur J-H. 2002. Latent infection by bovine herpesvirus type5 in experimentally infected rabbits: virus reactivation, shedding and recrudescence of neurological disease. Vet. Microbiol. 84(4):285-295.

Carrillo B.J., Ambrogi A., Schudel A.A., Vazquez M., Dahme E. \& Pospischil A. 1983. Meningoencephalitis caused by IBR virus in calves in Argentina. Zentralbl. Veterinärmed. B 30:327-332.

Chowdhury S.I., Lee B.J., Mosier D., Sur J.H., Osório F.A., Kennedy G. \& Weiss M.L. 1997. Neurophatology of bovine herpesvirus 5 (BHV-5) meningoencephalitis in a rabbit seizure model. J. Comp. Pathol. 117:295-310.

Delhon G., Moraes M.P., Lu Z., Afonso C.L., Flores E.F., Weiblen R., Kutish G.F. \& Rock D.L. 2003. Genome of bovine herpesvirus 5. J. Virol. 77:1033910347.

Dezengrini R., Weiss M., Torres F.D., Oliveira M.S., Furian A.F., Mello C.F., Weiblen R. \& Flores E.F. 2009. Bovine herpesvirus 5 induces an overproduction of nitric oxide in the brain of rabbits which correlates with virus dissemination and precedes the development of neurological signs. J. Neurovirol. 15:153-163.

Diel D.G., Almeida S.R., Brum M.C.S., Dezengrini R., Weiblen R. \& Flores E.F. 2007. Acute and latent infection by bovine herpesvirus type 5 in experimentally infected goats. Vet. Microbiol. 121:257-267.

Flores E.F. \& Donis R. 1995. Isolation of a mutant MDBK cell line resistant to bovine virus diarrhea virus (BVDV) due to a block in viral entry. Virology 208:565-575.

Flores E.F., Weiblen R., Vogel F.S.F., Dezengrini R., Almeida R.S., Spilki F. \& Roehe P.M. 2009. Neuropatogênese experimental da infecção pelo herpesvírus bovino tipo 5 em coelhos. Pesq. Vet. Bras. 29:1-16.

Kahrs R.F. 2001. Infectious bovine rhinotrachitis and infectious pustular vulvovaginitis, p.159-170. In: Kahrs R.F. (Ed.), Viral disease of cattle. Iowa State University Press, Ames.

Lindner A., Ambrosius H. \& Liebermann H. 1993. The development of an ELISA for the detection of antibodies against type 5 bovine herpesvirus (BHV-5) in sheep sera. Dtsch. Tierärztl. Wochenschr. 100:440-442.

Mayer S.V., Quadros V.L., Vogel F.S.F., Winkelmann E.R., Arenhart S., Weiblen R. \& Flores E.F. 2006. Dexamethasone-induced reactivation of bovine herpesvirus type 5 latent infection in experimentally infected rabbits results in a broader distribution of latent viral DNA in the brain. Braz. J. Med. Biol. Res. 39:335-343.

Meyer G., Lemaire M. \& Lyaku J. 1996. Establishment of a rabbit model for bovine herpesvirus type 5 neurological acute infection. Vet. Microbiol. 5:27-40.

Meyer G., Lemaire M., Ros K., Belak A., Gabriel D., Cassart E., Coignoul S., Belak S. \& Thiry E. 2001. Comparative pathogenesis of acute and latent infection of calves with bovine herpesvirus 5: comparison with bovine herpesvirus 1. Arch. Virol. 146:633-652.

Perez S.E, Bretschneider C., Leunda M.R., Osorio F.A., Flores E.F. \& Odeón A.C. 2002. Primary infection, latency and reactivation of bovine herpesvirus type 5 (BHV-5) in the bovine nervous system. Vet. Pathol. 39:437444. 
Reed L.J. \& Muench H. 1938. A simple method for estimating fifty per cent end points. Am. J. Hyg. 27:493-497.

Riet-Correa F., Vidor T., Schild A.L. \& Méndez M.C. 1989. Meningoencefalite e necrose do córtex cerebral em bovinos causadas por Herpes Vírus Bovino-1. Pesq. Vet. Bras. 9:13-16.

Rissi D.R., Rech R.R., Flores E.F., Kommers G.D. \& Barros C.L. 2007. Meningoencephalitis by bovine herpesvirus-5. Pesq. Vet. Bras. 27:251-260.

Salvador S.W.C., Lemos R.A.A., Riet-Correa F., Roehe P.M. \& Osorio A.L.A.R. 1998. Meningoencefalite em bovinos causada por herpesvírus bovino-5 no Mato Grosso do Sul e São Paulo. Pesq. Vet. Bras. 18:76-83.

Santos C.M.B., Anziliero D., Bauermann F.B., Brum M.C.S., Weiblen R. \& Flores E.F. 2010. Experimental infection of calves with bovine herpesvirus 5 recombinants defective in the genes encoding glycoprotein E, thymidine kinase or both. Pesq. Vet. Bras. (Submetido)

Silva A.M., Flores E.F.. Weiblen R., Canto M.C., Irigoyen L.F., Roehe P.M. \& Souza R.S. 1999a. Pathogenesis of meningoencephalitis in rabbits by bovine herpesvirus type-5 (BHV-5). Revta Bras. Microbiol. 30:22-31.

Silva A.M., Weiblen R., Irigoyen L.F., Roehe P.M., Sur H.J., Osorio F.A. \& Flo- res E.F. 1999b. Experimental infection of sheep with bovine herpesvirus type-5 (BHV-5). Vet. Microbiol. 66:89-99.

Silva S.C., Brum M.C., Weiblen R., Flores E.F. \& Chowdhury S.I. 2010. A bovine herpesvirus 5 recombinant defective in the thymidine kinase (TK) gene and a double mutant lacking TK and the glycoprotein E gene are fully attenuated for rabbits. Braz. J. Med. Biol. Res. 43:150159.

Studdert M.J. 1990. Bovine encephalitis herpesvirus. Vet. Rec. 126:21-22.

Vogel F.S.F., Lima M., Flores E.F., Weiblen R., Winkelmann E.R., Mayer S.V., Mazzutti K.C. \& Arenhart S. 2002. Replicação e excreção viral durante a infecção aguda e após a reativação da latência induzida por dexamethasona em bezerros inoculados com os herpesvírus bovino tipos 1 e 5 (BoHV-1, 5). Ciência Rural 43:1619-1621.

Vogel F.S.F., Caron L., Flores E.F., Weiblen R., Winkelmann E.R., Mayer S.V. \& Bastos R.G. 2003. Distribution of bovine herpesvirus type 5 DNA in the central nervous systems of latently, experimentally infected calves. J. Clin. Microbiol. 41:4512-4520.

Weiblen R., Barros C.S.L., Canabarro T.F. \& Flores E.F. 1989. Bovine meningoencephalitis from IBR virus. Vet. Rec. 25:666-667. 